\title{
Development of Water Intake Works Utilizing Wind Wave for Increasing Seawater Exchange in Fishing Port
}

\author{
AKTYOSHI NAKYAMA ${ }^{1}$, NOBUO TAKAKI ${ }^{1}$
}

1 National Research Institute of Fisheries Engineering, Fisheries Research Agency, Japan, Ebi-dai,
Hasaki-machi, Kashima-gun, Ibaragi-ken, Japan (tetugen@nrife.affrc.go.jp)

SUMMARY: Hydraulic experiments and some field surveys were conducted. Three types were developed by hydraulic experiments. They were found to have enough performance. But their performance was sensitive to tidal change because their principle was converting wave momentum near water surface into inflow. To maintain their performance well against large tidal range, the simple way was developed. Dissolved oxygen of generated inflow was found to be almost saturated every time because of mixing air and water at this facility. Generated inflow rate could be estimated by the developed numerical model and experimental formula.

\section{KEY WORDS: Water-intake works, Water Purifying}

\section{INTRODUCTION}

In Japan, many calm basins of fishing ports are used for live fish stock to supply fresh and valuable fish to Japanese people. Moreover these basins are requested to be used for nursery culture before seed liberation. So improvement and conservation of seawater quality in basins is increasing its importance.

In order to improve or maintain seawater quality in basins, it is necessary to construct wastewater treatment works and sea water intake works which bring clean seawater to basins. At the fishing ports of which scale is small or medium and seawater interchange efficiency is not so high, Water Intake Works is effective. For bringing clean seawater to the basin, it is economical to utilize natural power such as tidal motion, wind waves, internal waves. Some methods have been studied up to now, but almost of studies are about utilizing tidal motion.

Authors have been developing Water Intake Works which is effective to exchange seawater by utilizing wind waves even if wave height is relatively small. Some kinds of Water Intake Works were developed by hydraulic model tests and numerical simulations ${ }^{1)^{-10}}$. And they were constructed or adopted as Fishing Port Construction Plan.

\section{STRUCTURE AND PRINCIPLES}

Its basic structure is composed of a breakwater with training channels, a pool, and a submerged mound(Fig.1). Wind waves breaking at the submerged mound cause wave-set up at the pool between the breakwater and the submerged mound. So mean water level at the pool is

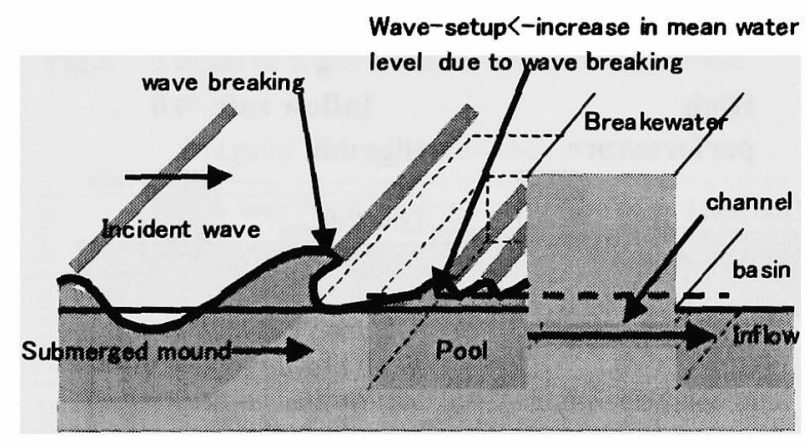

Fig. 1 Structure and principle of water intake works utilizing wind wave

higher than the one at the basin behind the breakwater. And seawater flow continuously from the seawater pool to the basin through the training channels as long as incident wave height is over $0.3 \mathrm{~m}$. And inflow rate for given wave height can be calculated from hydraulic model equation" (not introduced in this report due to limited space).

\section{ITS PERFORMANCE}

The original type was constructed at the Shikanoshima fishing port in 1991 (fig.2). We carried out field survey before and after construction. And its performance was found to be very high. Mean inflow rate was about $100,000 \mathrm{~m}^{3} /$ day when mean wave height was $0.6 \mathrm{~m}$. Flow from the channels to the basin is shown in photo 1 .

Dissolved oxygen of inflow was found to be always saturated from field survey. This facility transport not only sea water but also oxygen to the basin.

But it is clear that its performance became low in case of 

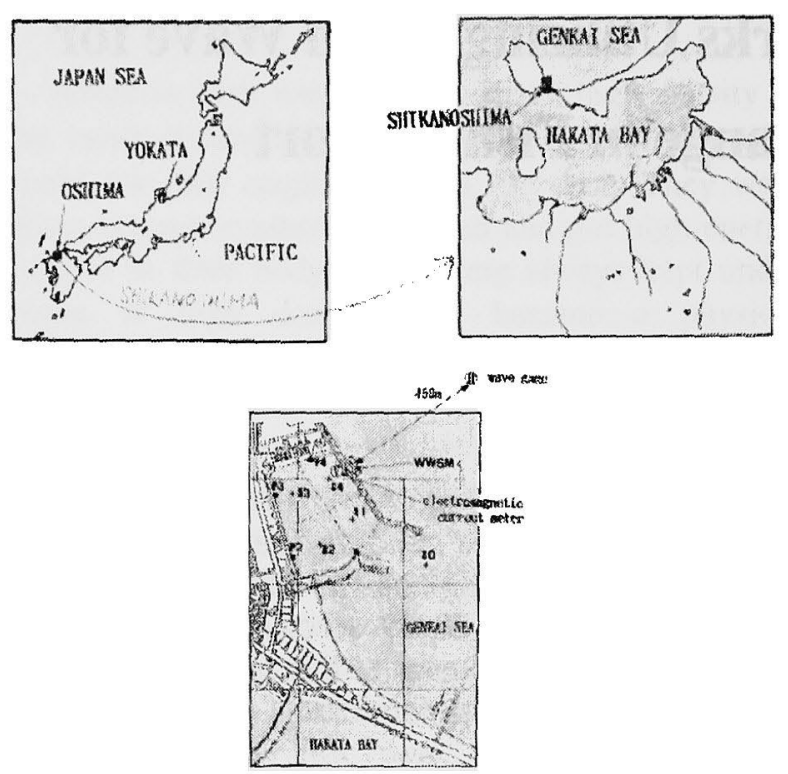

Fig.2 Location of the Shikanoshima Fishing Port

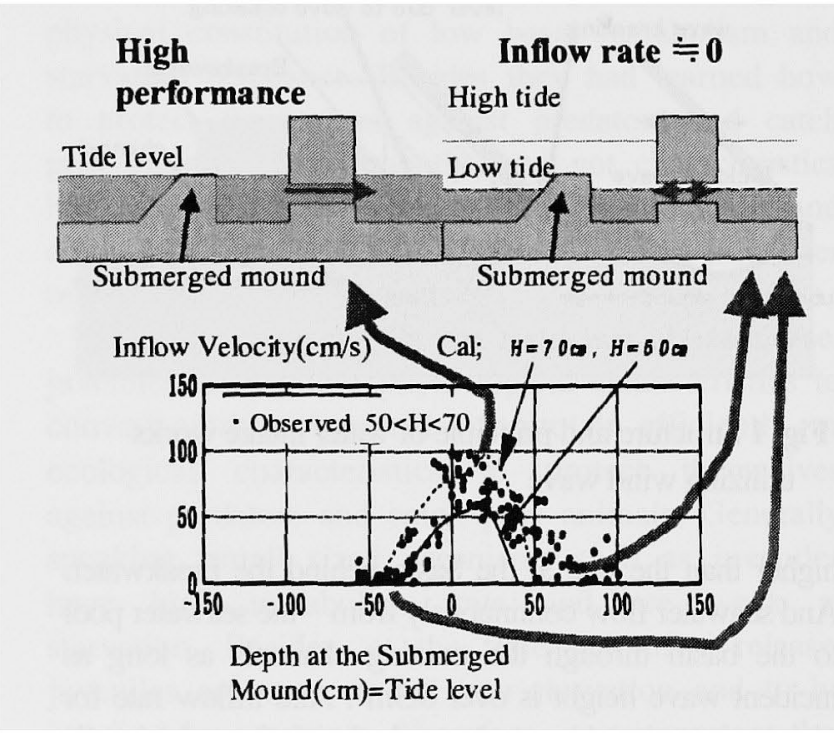

Fig.3 Measured inflow velocity at the Shikanoshima Fishing port

high and low tide level (Fig.3). This weak point was already recognized from hydraulic experiments.

\section{IMPROVING ITS STRUCTURE FOR TIDAL CHANGE $^{2), 4)}$}

In order to maintain its performance against large tidal range, hydraulic model tests were carried out. And we developed the water intake works(Step Submerged Mound type) composed of multi submerged mounds of which crown height was different from each other (fig.4).

Fig.5 shows that inflow velocity reduction is not so

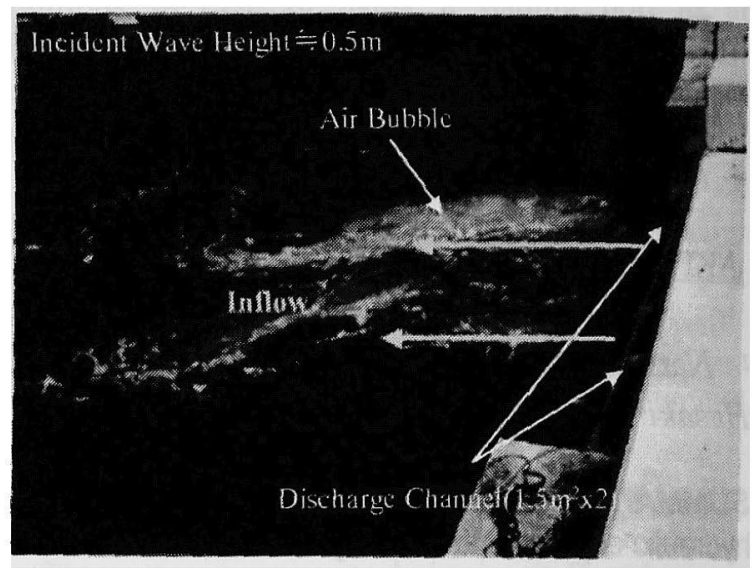

Photo 1 Flow from the channels

large at any tide level except highest and lowest tide level. And inflow velocity depends strongly upon incident wave height as shown in this figure. This type was adopted at the Imaizumi Fishing port located in southern part of Japan where maximum tidal change was about $3 \mathrm{~m}$.

Sea water exchange rate in Imaizumi fishing port was estimated by simulating tidal flow and inflow induced by water intake works. Fig.6 shows dispersion of water

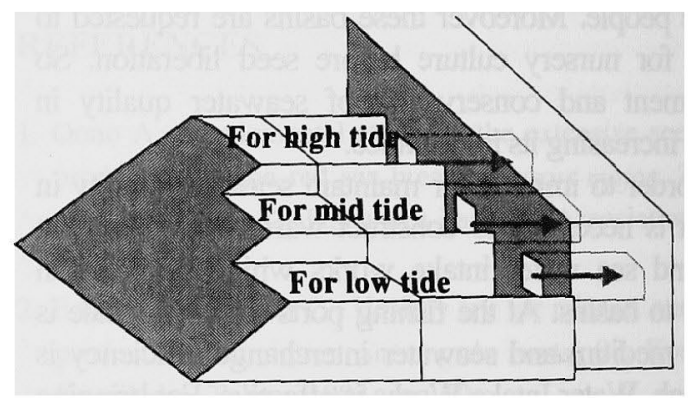

Fig.4 Step Submerged Mound type

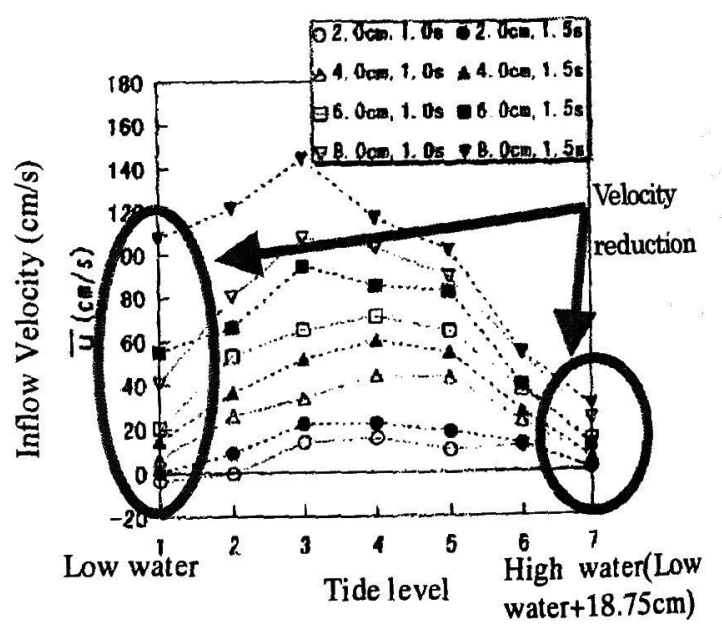

Fig.5 Inflow velocity of Step Submerged Mound type 
Tidal Motion Only

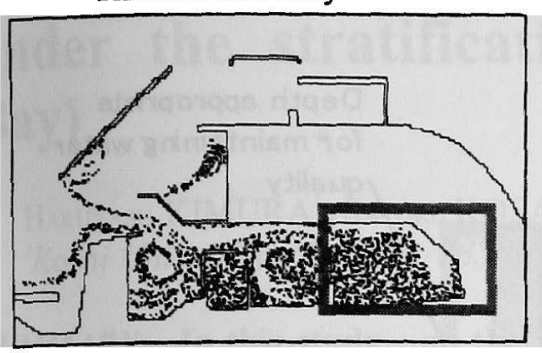

Tidal Motion+Inflow $1 \mathrm{~m}^{3} / \mathrm{s}$

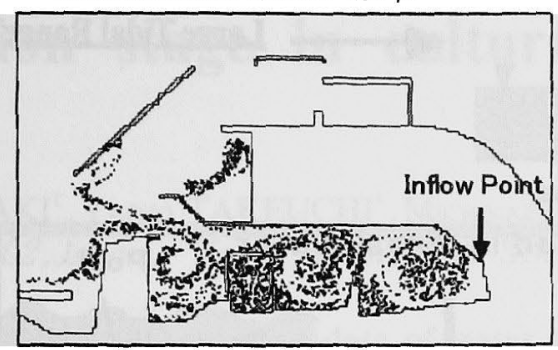

Tidal Motion + Inflow $2 \mathrm{~m}^{3} / \mathrm{s}$

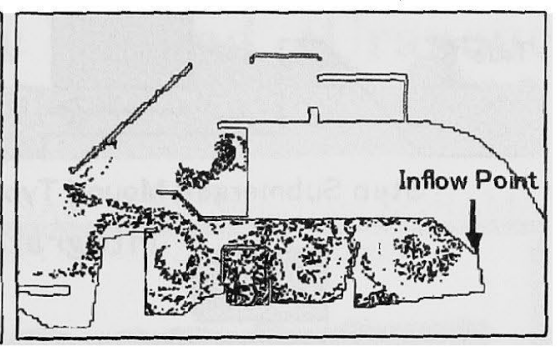

Fig.6 Calculated remaining water particles during a period of tide

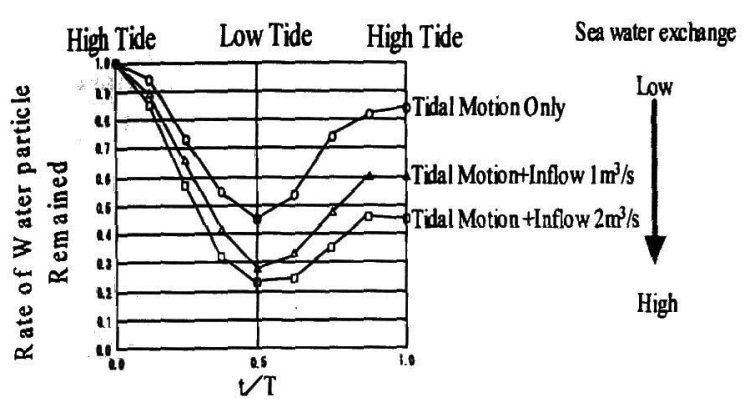

Fig.7 Rate of remained water particles in the basin

particles in the fishing port during a period of tide.

Exchange rate is not so large in case of tidal motion only. Considerable amount of water particles in the basin discharged at ebb current stage, but most of them come back at flood current stage. White area in the fishing port becomes lager according to increase in inflow rate. White area means outer sea water into the fishing port.

Fig. 7 shows rate of remaining water particles in the basin shown as rectangular frame in Fig.6. It is made clear that water intake works improved sea water exchange rate drastically. And inflow may include a lot of dissolved oxygen due to wave breaking on the submerged mound as already mentioned in "ITS PERFORMANCE". Dissolved oxygen contributes to the aerobic digestion and controls the dissolution of nutrients from bottom sediments.

\section{DEVELOPMENT OF ANOTHER WATER INTAKE WORKS}

Submerged mound type is expensive in case of deep water $(>10 \mathrm{~m})$ because large amount of rocks or armor blocks for submerged mound is needed. So we developed another type by hydraulic model experiments. Their principle is also to convert wind wave

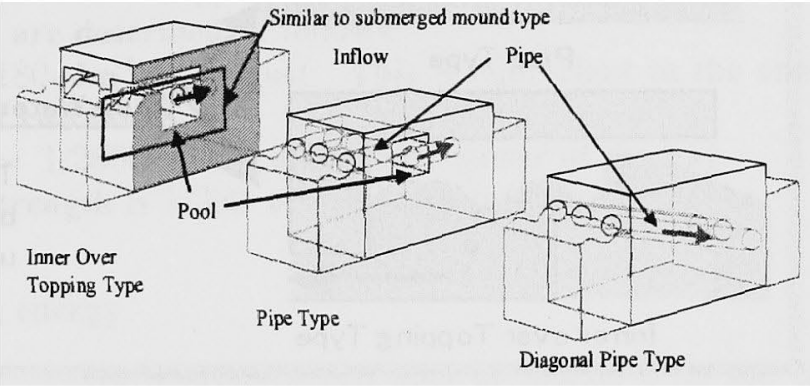

Fig.8 3 types of water intake works for deep water

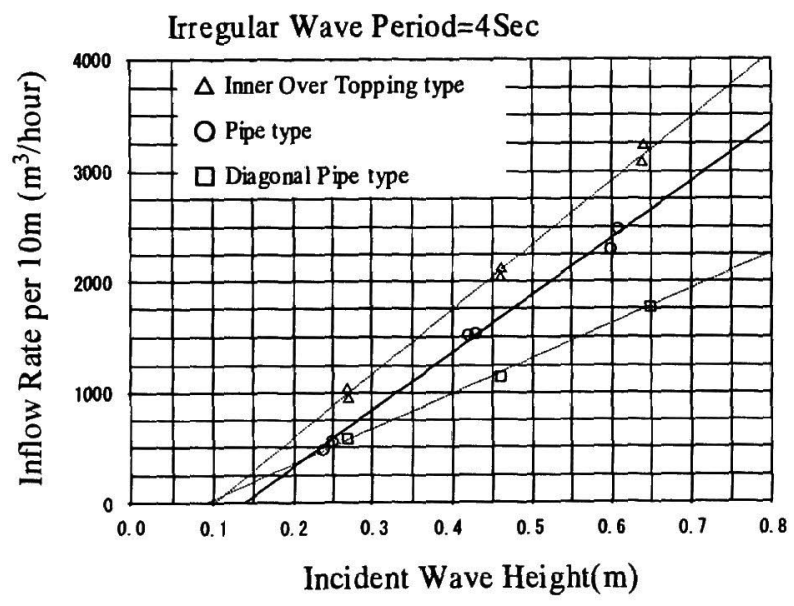

Fig. 9 Relationship between inflow rate of each type and incident wave height

momentum into the inflow. Its structure was integrated in the breakwater because of construction cost (fig.8).

Fig. 9 shows results of hydraulic model tests. Inner over topping type have highest performance. Pipe type is second. For all types, relationship between inflow velocity and incident wave height is almost linear.

\section{CONCLUSIONS}

1)In case of shallow water region, submerged mound type 


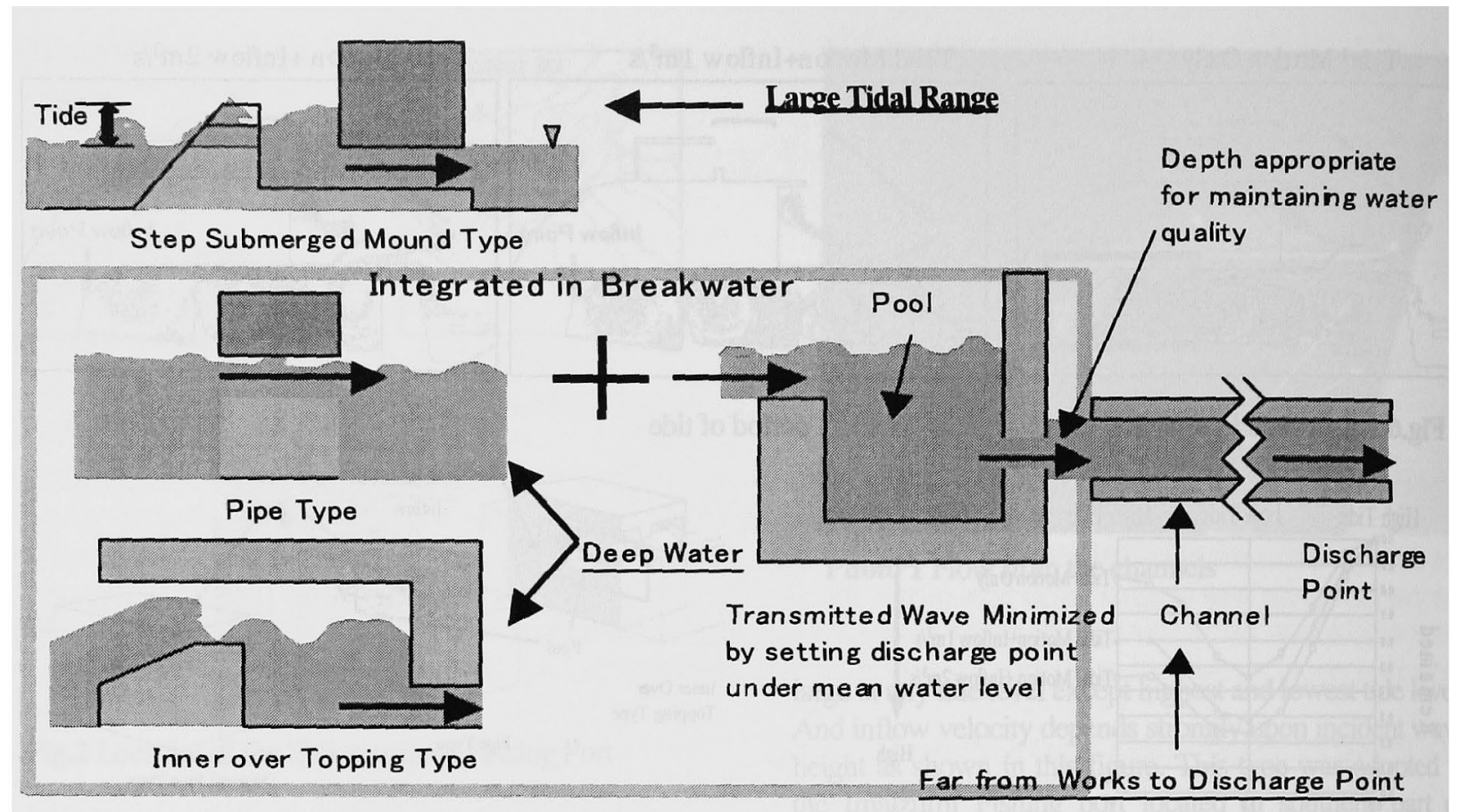

Fig. 10 Summary of this study

was appropriate to enhance seawater exchange rate in basin.

2)In case of deep water region, another types were developed.

3)In case of large tidal range region, the applicable structures were developed.

4) Enhancing seawater exchange rate in a fishing port is possible by constructing water intake works appropriate to topography, wave condition, required seawater quality at the site.

Fig.10 shows the outline of this study.

\section{REFERENCE}

1. Nakanishi,T. Nakayama,A. Shikata,S. Sami,M. Onishi,A. and Yasuda. A Study on Preservation of Seawater Quality in Closed Fishery Harbor. Proceedings of Coastal Engineering 1999; 46: 1201-1205. In Japanese.

2. Ohmura.Y, Nakayama. A Research on Applicability Enhancement of Seawater Intake Works with Submerged Mounds. Technical report of national research institute of fisheries engineering, aqua culture and fishing port engineering 1998; 20: 1-11. In Japanese with English absrract.

3. Yamamoto.J, Nakayama,A. Nakamura. K. Experimental Study on the Water-Intake Works at the Deep Water. Technical report of national research institute of fisheries engineering, aqua culture and fishing port engineering 1997; 19: 45-56. In Japanese with English absrract.

4. Ohmura.Y, Nakayama.A, Maekawa,H. Seawater Exchange Using Seawater Intake Works at a Fishing Port with Wide Tidal Range. Proceedings of Coastal Engineering 1997; 44: 986-990. In Japanese.
5. Yamamoto.J, Takeuchi.T, Nakayama.A, Tabata,S, Ikeda,M. Field survey on environmental effects of the Water Intake Works constructed at the Shikanoshima fishing port. Proceedings of Coastal Engineering 1994; 41: 1096-1190. In Japanese.

6. Nakayama.A, Yamamoto.M, Yamamoto.J, Moriguchi,A. Development of Water-Intake Works with Submerged Mound(WWSM). The International Conference on Hydro-Technical Engineering for Port and Harbor Construction 1994, 823-842.

7. Yamamoto.M. Design for Water-intake Works with a Submerged Mound. Technical report of national research institute of fisheries engineering, aqua culture and fishing port engineering 1994; 16: 1-12. In Japanese with English abstract.

8. Yamamoto.M, Nakaizumi,M, Moriguchi.A. Development of the Breakwater with Submerged Mound for Sea Water Interchange. Bulletin of National Research Institute of Fisheries Engineering 1992; 13: 11-30. In Japanese with English absrract.

9. Yamamoto.M, Manabe.M, Nakaizumi.M. Development of the break water with remote submerged rubble mound for the purpose of interchanging sea water (1). Technical report of national research institute of fisheries engineering, aqua culture and fishing port engineering 1988; 10: 39-56. In Japanese with English abstract.

10. Manabe,M., Nakaizumi,M. and Yamamoto,N. Development of the break water with remote submerged rubble mound for the purpose of interchanging sea water(2). Proceedings of coastal engineering, 1988; 35: 632-636. In Japanese with English abstract. 